\title{
EDITORIAL
}

\section{Dengue Protection and Cure: Bangladesh Perspective}

\author{
Abdul Kader Mohiuddin ${ }^{1 *}$
}

${ }^{1}$ World University of Bangladesh, BANGLADESH

*Corresponding Author: trymohi@gmail.com

Citation: Mohiuddin, A. K. (2020). Dengue Protection and Cure: Bangladesh Perspective. European Journal of Sustainable Development Research, 4(1), em0104. https://doi.org/10.29333/ejosdr/6260

The evidence of the use of plants for medicinal purposes dates as far back as 60,000 years ago. Recently, the WHO estimated that $80 \%$ of people worldwide rely on herbal medicines for some aspects of their primary healthcare needs. Among 250,000 to 500,000 species of plants on earth, 35000 are used worldwide for medicinal purposes, 20000 medicinal plants are available in Indian subcontinent, some 3000 have shown potential in cancer, 1200 in diabetes and 2000 in pest control programs. Worldwide, mosquitos transmit disease to more than 700 million people (Ryan et al., 2019). Among them, 390 million were affected with dengue every year before 2013 and approximately 3.9 billion people live in dengue endemic countries. 2.4 million people are infected with dengue each year in Bangladesh. After chikungunya outbreak, 2008-2017 in Bangladesh, the daredevil mosquitos have created a horror situation with dengue fever. More than 50000 infected in more than 50 districts (among 68) in August alone (Alam, 2019) and some people around keep saying that almighty is punishing people like he punished Nomrud, the most powerful king of his time, who was defeated by one weak mosquito. Fact is, we are still lack behind actual measures.

The first licensed dengue vaccine, Dengvaxia ${ }^{\circledR}$ (Sanofi), received regulatory approval in a number of countries but had some limitations (Prompetchara et al. 2019). Costs of 2 other live-attenuated vaccine candidates, DENVax (Japan) and TV003/TV005 (US) are not within the range of average people. In Indonesia Dengvaxia ${ }^{\circledR}$ costs about US\$207 for the recommended three doses (TEMPO.CO 2016). Some available mosquito repellant creams are hiking 10 times price than actual price, so how much Dengvaxia ${ }^{\circledR}$ will hike, if available, we can very well imagine. And which mosquito borne disease will be epidemic next time is uncertain. So, we have to focus on mosquito bite prevention, not dengue or chikungunya.

Climate change is a very important factor of Flavivirus (genus type of dengue virus) transmission but not the sole factor. Along with climate change, aberrant use of pesticides and their resistance is also noted in recent dengue affected countries (Bharati and Saha 2018). Most commonly used insecticides in households (metafluthrin \& D-allethrin), mosquito coils repel mosquito and kerosene fog by city corporation kills larvae and ensures effective adult mosquito eradication for short-term. The use of coil protective stands is necessary to prevent fire incident and accidental touch. Mosquito proof nets are applied in many household and air blower in a few supermarket entrances are not enough for disease prevention and mostly unaffordable/unsuitable for general use. Full-sleeve cloths can reduce mosquito bite incidents but rarely ensures prevention from mosquito transmitted viral diseases. Permethrin-treated military clothing has shown to be effective in significantly reducing mosquito bites in the covered regions (Achee et al., 2019). There is also an abundance of fixed or moveable electric devices (for example mosquito bats or electric coils) and wearable devices that are available, including: bracelets, sonic devices, clothing, and skin patches. Their accessibility, availability, affordability and practical uses varied among general people.

There are a few common misconceptions like garlic is an effective repellent. Topical application of garlic oil and garlic consumption with vitamin B supplements have not been shown to be effective at repelling mosquitoes. But garlic essential oil can be an effective pesticide against mosquitoes when microencapsulated and used in an attractive toxic sugar baits system (Muturi et al., 2018). Jhar-fuk is very common in rural Bangladesh where the traditional healer or hujur/moulvi chants from the holy book and blow on the body of the sick people. Many fake herbal or homeopathic liver tonics are available in the market claiming improved platelet count after use. A common tale told by people "burning one mosquito coil in a closed room amounts to smoking roughly 100 cigarettes" has little scientific value. It's true that a burning coil has health effect but it's better than having deadly mosquito bites. The key message should be to avoid prolonged exposure, especially in enclosed spaces. Some smokers give it a reason that smoking prevents mosquito bites. May be this is true, not because of cigarette smoke but because of smoking induced declined hemoglobin count. The effect of smoking on platelet count is still controversial. Aedes aegypti mosquitoes (the main vector of dengue) are known to bite during the daytime hours. It does not spare use of mosquito-nets during night-time sleep in this hot and humid weather, rather encourage use of the same during daytime sleeping. Parks and lakes are where people get mosquito bites frequently. It is better walking/running there and leave the place soon after finishing walk avoiding idle sitting back

Copyright (c) 2020 by Author/s and Licensed by Modestum Ltd., UK. This is an open access article distributed under the Creative Commons Attribution License which permits unrestricted use, distribution, and reproduction in any medium, provided the original work is properly cited. 
and gossip. Since platelet count is compromised, conventional painkillers other than paracetamol should be avoided strictly because of their negative impression on platelet count (Prompetchara et al., 2019).

Infants and youngsters (age below 20) mostly attract mosquitos due to high hemoglobin content. If we go back to plant derived mosquito repellents, we have a few options for topical use. Topical application of neem, lemongrass, peppermint and eucalyptus oil have equivalent efficacy of DEET (banned in Denmark, EU, US, UAE, Canada but available in Bangladesh) but relatively safe in use. Conventional topical cream diethyl benzamide (ODOMOS/TRIG) also shows significant dermal and neurotoxicity. Their use should be limited to feet and ankles. Burning neem leaves provided nearly $80 \%$ protection against mosquitoes for 2 hours. However, to get similar efficacy like eucalyptus oil, more than 20 times higher concentration of neem oil was required (Kaura et al., 2019). Neem (Azadirachta indica) infused water, papaya leaf juice and green chirata (Andrographis paniculata) have shown to increase both blood platelets and WBC count, two of which are the worst side effects of dengue fever. However, none of the above mentioned have been reported as safe in infant and pregnant women. Long-term exposure to lemongrass (Cymbopogon flexuosus), peppermint (Mentha piperita) and eucalyptus oil (Eucalyptus globulus) may impart toxic side effects. Also, Ripe papaya during pregnancy may not pose any significant danger. Drinking papaya juice with a few lemons drops in it may also work (Adebiyi et al., 2002). Folate and iron rich foods, Vitamins B-12, C, D and K improve platelet count. Plenty of liquids like orange juices, coconut water, ginger water and ORS water are recommended to keep the body hydrated. Cranberry juice, grape seeds, pomegranate and unripe apple peels are rich in flavonoids like quercetin and fisetin, downregulate proinflammatory cytokines induced by dengue virus (Jasso-Miranda et al., 2019).

\section{REFERENCES}

Achee, N. L., et al. (3 January 2019). Alternative strategies for mosquito-borne arbovirus control. PLoS neglected tropical diseases, 13(1), e0006822. https://doi.org/10.1371/journal.pntd.0006822

Adebiyi, A., Adaikan, P. G., \& Prasad, R. N. (2002). Papaya (Carica papaya) consumption is unsafe in pregnancy: fact or fable? Scientific evaluation of a common belief in some parts of Asia using a rat model. Br J Nutr., 88(2), $199-203$. https://doi.org/10.1079/BJN2002598

Alam, H. (31 August 2019). Dengue Patients: August sees more than 19-yr total 50,974 cases recorded in 30 days. The Daily Star.

Bharati, M., \& Saha, D. (10 September 2018). Multiple insecticide resistance mechanisms in primary dengue vector, Aedes aegypti (Linn.) from dengue endemic districts of sub-Himalayan West Bengal, India. PloS one, 13(9), e0203207. https://doi.org/10.1371/journal.pone.0203207

Jasso-Miranda, C., et al. (1 July 2019). Antiviral and immunomodulatory effects of polyphenols on macrophages infected with dengue virus serotypes 2 and 3 enhanced or not with antibodies. Infection and drug resistance, 12, $1833-1852$. https://doi.org/10.2147/IDR.S210890

Kaura, T., et al. (2019). Utilizing larvicidal and pupicidal efficacy of Eucalyptus and neem oil against Aedes mosquito: An approach for mosquito control. Tropical parasitology, 9(1), 12-17. https://doi.org/10.4103/tp.TP_35_18

Muturi, E. J., et al. (2018). Ovicidal and Larvicidal Effects of Garlic and Asafoetida Essential Oils Against West Nile Virus Vectors. Journal of insect science, 18(2), 43. https://doi.org/10.1093/jisesa/iey036

Prompetchara, E., Ketloy, C., Thomas, S. J., \& Ruxrungtham, K. (13 January 2019). Dengue vaccine: Global development update. Asian Pac J Allergy Immunol. https://doi.org/10.12932/AP-100518-0309

Ryan, S. J., Carlson, C. J., Mordecai, E. A., \& Johnson, L. R. (2019). Global expansion and redistribution of Aedes-borne virus transmission risk with climate change. PLoS Negl Trop Dis., 13(3): e0007213. https://doi.org/10.1371/journal.pntd.0007213

TEMPO.CO. (17 October 2016). Dengue Fever Vaccine Available in Indonesia. Sci \& Tech. 